\title{
Intraoperative cerebral oximetry-based management for optimizing perioperative outcomes: a meta-analysis of randomized controlled trials
}

\section{Gestion peropératoire basée sur l'oxymétrie cérébrale pour améliorer les résultats périopératoires : méta-analyse d'essais randomisés contrôlés}

\author{
Andres Zorrilla-Vaca, BSc (1) - Ryan Healy, BSc - Michael C. Grant, MD • \\ Brijen Joshi, MD • Lucia Rivera-Lara, MD • Charles Brown, MD • \\ Marek A. Mirski, MD, PhD \\ Received: 19 July 2017/Revised: 10 December 2017 / Accepted: 10 December 2017/Published online: 18 January 2018 \\ (C) Canadian Anesthesiologists' Society 2018
}

\begin{abstract}
Purpose Although evidence from observational studies in a variety of clinical settings supports the utility of cerebral oximetry as a predictor of outcomes, prospective clinical trials thus far have reported conflicting results. This systematic review and meta-analysis was designed to evaluate the influence of management associated with intraoperative cerebral oximetry on postoperative outcomes. The primary outcome was postoperative cognitive dysfunction (POCD), with secondary outcomes that included postoperative delirium, length of intensive care unit (ICU) stay, and hospital length of stay (LOS).
\end{abstract}

Electronic supplementary material The online version of this article (https://doi.org/10.1007/s12630-018-1065-7) contains supplementary material, which is available to authorized users.

A. Zorrilla-Vaca, BSc

School of Medicine, Universidad del Valle, Hospital

Universitario del Valle, Cali, Colombia

A. Zorrilla-Vaca, BSc $(\square)$

Program of Medicine and Surgery, Faculty of Health,

Universidad del Valle, Cll 5B No. 36 - 00, Cali Postal code:

760026, Colombia

e-mail: andres.zorrilla@correounivalle.edu.co

R. Healy, BSc · M. C. Grant, MD · B. Joshi, MD .

C. Brown, MD - M. A. Mirski, MD, PhD

Department of Anesthesiology \& Critical Care Medicine, The Johns Hopkins University School of Medicine, Baltimore, MD, USA

L. Rivera-Lara, MD

Department of Neurology, The Johns Hopkins University School of Medicine, Baltimore, MD, USA
Source After searching the PubMed, EMBASE, Cochrane Library, Scopus, and Google Scholar databases, all randomized controlled trials (RCTs) assessing the impact of intraoperative cerebral oximetry-guided management on clinical outcomes following surgery were identified.

Principal findings Fifteen RCTs comprising 2,057 patients $(1,018$ in the intervention group and 1,039 in control group) were included. Intraoperative management guided by the use of cerebral oximetry was associated with a reduction in the incidence of POCD (risk ratio [RR] 0.54; 95\% confidence interval [CI], 0.33 to 0.90; $P=0.02$; $\left.I^{2}=85 \%\right)$ and a significantly shorter length of ICU stay (standardized mean difference [SMD], $-0.21 \mathrm{hr} ; 95 \% \mathrm{CI}$, -0.37 to $\left.-0.05 ; P=0.009 ; I^{2}=48 \%\right)$. In addition, overall hospital LOS (SMD, -0.06 days; $95 \%$ CI, -0.18 to 0.06; $P$ $\left.=0.29 ; I^{2}=0 \%\right)$ and incidence of postoperative delirium (RR, 0.69; 95\% CI, 0.36 to 1.32; $P=0.27 ; I^{2}=0 \%$ ) were not impacted by the use of intraoperative cerebral oximetry.

Conclusions Intraoperative cerebral oximetry appears to be associated with a reduction in POCD, although this result should be interpreted with caution given the significant heterogeneity in the studies examined. Further large (ideally multicentre) RCTs are needed to clarify whether POCD can be favourably impacted by the use of cerebral oximetry-guided management.

Résumé

Objectif Alors que les données probantes provenant d'études observationnelles réalisées dans différents cadres cliniques témoignent de l'intérêt de l'oxymétrie cérébrale comme élément prédictif des résultats, les essais 
cliniques prospectifs ont - jusqu'à ce jour - fourni des résultats contradictoires. Cette étude et méta-analyse systématique a été conçue pour évaluer l'influence de la gestion associée à l'oxymétrie cérébrale peropératoire sur les résultats postopératoires. Le critère d'évaluation principal était la dysfonction cognitive postopératoire $(P O C D)$ et les critères d'évaluation secondaires étaient, notamment, le délirium postopératoire, la durée du séjour en unité de soins intensifs (USI) et la durée de séjour à l'hôpital (DSH).

Source Après une recherche dans les bases de données PubMed, EMBASE, Cochrane Library, Scopus et Google Scholar, tous les essais contrôlés randomisés (ECR) évaluant l'impact de la gestion peropératoire guidée par l'oxymétrie cérébrale sur les résultats cliniques postopératoires ont été identifiés.

Constatations principales Quinze essais cliniques randomisés ayant inclus 2057 patients (1 018 dans le groupe interventionnel et 1039 dans le groupe témoin) ont été inclus. La gestion peropératoire guidée par l'utilisation de l'oxymétrie cérébrale a été associée à une réduction de l'incidence du POCD (rapport de risque [RR] 0,54; intervalle de confiance à $95 \%$ [IC]: 0,33 à 0,90; $\left.P=0,02 ; I^{2}=85 \%\right)$ et à une plus brève durée de séjour en USI (différence moyenne standardisée [SMD] : $-0,21 \mathrm{~h}$; IC à $95 \%$ : $-0,37$ à $-0,05 ; \quad P=0,009$; $\left.I^{2}=48 \%\right)$. De plus, la durée de séjour globale à l'hôpital (SMD : -0,06 jour; IC à $95 \%$ : $-0,18$ à 0,06; $\left.P=0,29 ; \quad I^{2}=0 \%\right)$ et l'incidence $d u$ delirium postopératoire (RR: 0,69; IC à $95 \%: 0,36$ à 1,32; $\left.P=0,27 ; \quad I^{2}=0 \%\right)$ n'ont pas été affectées par l'utilisation de l'oxymétrie cérébrale peropératoire.

Conclusions L'oxymétrie cérébrale peropératoire semble associée à une réduction du POCD, mais ce résultat doit être interprété avec prudence compte tenu de l'importante hétérogénéité entre les études analysées. D'autres essais cliniques randomisés avec suffisamment de patients (idéalement multicentriques) sont nécessaires pour savoir si le POCD peut être favorablement influencé par l'utilisation de la gestion cérébrale guidée par oxymétrie.

Cerebral oximetry uses near-infrared spectroscopy (NIRS) to provide real-time non-invasive interrogation of regional cerebral oxygen saturation $\left(\mathrm{rSO}_{2}\right)$ and has become an increasingly popular intraoperative monitoring technique. ${ }^{1}$ Measuring $\mathrm{rSO}_{2}$ in a representative volume of frontal cortex brain tissue (and assuming stable metabolic suppression of the brain under anesthetic conditions), it has been seen as a surrogate of cerebral blood flow and thus as a useful technology to detect cerebral hypoperfusion. ${ }^{1,2}$ It is thought to be particularly beneficial in the perioperative setting when hemodynamic fluctuations often occur that can lead to postoperative complications such as cognitive impairment or delirium. $^{2-6}$ Anesthesiologists have utilized cerebral oximetry monitoring in an attempt to optimize both blood pressure and oxygen delivery to maintain adequate cerebral perfusion and decrease the incidence of these neurocognitive complications. ${ }^{2,5}$

Several observational studies have pointed to the predictive value of cerebral oxygenation monitoring for both short- and long-term functional outcomes. ${ }^{7-9}$ It has been suggested that in cardiac surgery patients, in addition to those following cardiac arrest or with a diagnosis of sepsis, $\mathrm{rSO}_{2}(<60 \%)$ may be associated with an increased risk of adverse outcomes. ${ }^{10-12}$ An additional study in aortic arch surgery patients concluded that reduced intraoperative cerebral oxygen saturation was not only associated with extended hospital stay, but also increased overall hospital costs. ${ }^{13}$ Furthermore, given an inherent increase in the physical and financial burden of patient care associated with cognitive dysfunction following surgery, ${ }^{14}$ additional efforts directed towards cerebral monitoring and postoperative cognitive dysfunction (POCD) prevention are warranted. Although cerebral oximetry monitoring has been available as a clinical tool for two decades, little consensus exists regarding the role of cerebral oximetrybased management in the perioperative period. Several prospective trials have attempted to assess the impact of cerebral oximetry on postoperative cognitive outcomes; however the results have remained conflicting.

The purpose of this systematic review and meta-analysis was to determine the overall beneficial effect of cerebral oximetry on select outcomes after surgery.

\section{Methods}

This meta-analysis followed the guidelines outlined by the Preferred Reporting Items for Systematic Reviews and Meta-Analyses statement. ${ }^{15}$ It was also registered on the International Prospective Systematic Reviews Registry database (PROSPERO 2017: CRD42017057293) on 14 February 2017.

Search strategy

The MEDLINE/PubMed, EMBASE, Cochrane Library, Scopus, and Google Scholar databases were searched from inception to 2 December 2017 for randomized-controlled trials (RCTs) assessing the effects of intraoperative cerebral oximetry monitoring on postoperative outcomes following cardiac and non-cardiac surgery. There was no restriction on language. In addition, article citations were 
reviewed to ensure inclusion of relevant studies not captured in our initial literature search. The clinicaltrials.gov registry was also searched to evaluate for any ongoing RCT where results might be expected to be published in the near future. Two authors (A.Z.V. and R.J.H.) reviewed the literature and screened the abstracts independently. Full-text articles that met the inclusion criteria were reviewed for detailed comprehension and further assessment of the quality and risk of bias. All disagreements between reviewers in the selection and evaluation processes were resolved by discussion with a third reviewer (M.C.G.). All demographic data, including year of publication, sample size, intervention algorithm, type of surgery, anesthetic management, and specified outcomes, were abstracted in a predefined manner.

\section{Eligibility criteria}

We limited our meta-analysis to RCTs of adult patients (age $>18 \mathrm{yr}$ ) who underwent either cardiac or non-cardiac surgery. The intervention group was monitored with NIRS (interventions specified below) while the control group was not.

\section{Interventions considered}

Management guided by the use of intraoperative cerebral oximetry was considered the primary intervention and was triggered by evidence of cerebral oxygen desaturation. Specific interventions included the use of fluids and/or vasopressors for hypotension, an increase in pump flow to maintain the cardiac index above $2 \mathrm{~L} \cdot \mathrm{m}^{-2} \cdot \mathrm{min}^{-1}$, changes in ventilatory parameters (i.e., optimizing the partial pressure arterial oxygen and carbon dioxide), and blood transfusion if anemic. Thresholds for intervention were generally an $\mathrm{rSO}_{2}<55-60 \%$ or $\mathrm{rSO}_{2}<75 \%$ of baseline. Prior experimental work has suggested that critical neurologic deficits are more likely to occur with more than a $30 \%$ reduction in $\mathrm{rSO}_{2},{ }^{16}$ and to establish a rational approach, our search also involved the selection of studies wherein a more conservative intervention threshold was utilized. $^{17}$

\section{Outcomes}

The primary outcome in this meta-analysis was the incidence of POCD as defined by the individual studies. Most articles used a combination of standardized assessments of cognitive functions such as the MiniMental Status Examination (MMSE), grooved pegboard, anti-saccadic eye movement, color trail, and Montreal Cognitive Assessment. Secondary outcomes included intensive care unit (ICU) length of stay (LOS), overall hospital LOS, as well as the incidence of total transfusion, delirium, surgical site infection, cardiac complications, and mortality. Individual study definitions were also used for secondary outcomes. The time interval to evaluate delirium and POCD outcomes was within one week after surgery.

Assessment of methodologic quality and quality of evidence

Methodologic quality assessment was performed using the Cochrane risk of bias tool for randomized studies. ${ }^{18}$ Each study was assessed based upon seven domains of potential bias (random sequence generation, allocation concealment, blinding of intervention, blinding of outcome assessment, incomplete outcome data, selective reporting, and other bias). The overall risk of bias of individual studies was classified as high if at least one domain was determined at high risk or if there were more than two domains of unclear risk, moderate if at least two domains were determined at unclear risk, and low if all the domains were determined at low risk. The quality of the evidence provided in this metaanalysis was also assessed using five levels of evidence, ranging from level I to III with three subcategories in level II, as previously reported. ${ }^{19}$

\section{Statistical analysis}

Initially, an exploratory qualitative analysis was conducted to describe the characteristics of the studies included in this meta-analysis. The incidence of POCD was extracted as a dichotomous variable (present or absent) and compared using risk ratios (RR) with their respective $95 \%$ confidence intervals (CI). We used forest plots to illustrate the estimations and overall effect sizes with pooled RR represented as a solid diamond at the bottom of the forest plot. Outcomes presented as continuous variables were compared using the standardized mean difference (SMD). In cases of publication of median values with their ranges, we converted these measures into mean and standard deviations (SD) using the method of Wan et al. ${ }^{20}$ In cases where $95 \%$ CI of mean values was included, the SD was calculated using a standard formula. Predetermined subgroup analyses were performed based upon type of surgery (cardiac versus non-cardiac surgery) and type of cerebral oximetry-based intervention. Sensitivity analysis was performed based upon overall study quality (high or moderate versus low) as determined by quality of evidence assessment.

Heterogeneity $\left(I^{2}\right)$ was assessed using the correspondent Chi-squared test $\left(I^{2}<50 \%\right.$ and $I^{2}>50 \%$ were considered insignificant and significant heterogeneity, respectively). Publication bias was calculated using the Begg's and Egger's tests ${ }^{21}$ with funnel plots constructed to represent 
any tendency for publishing in favour of positive effects. Significant publication bias was considered when there was asymmetry in the funnel plot and a statistically significant bias coefficient was noted on the Beggs's test. ${ }^{21} P<0.05$ was considered statistically significant for all the statistical tests. All analyses were performed using a random-effect model (DerSimonian and Laird method). ${ }^{22}$ All statistics were performed using Review Manager 5.3 (Cochrane Collaboration, Oxford, UK) or Stata version 13.0 (Stata, College Station, TX, USA).

\section{Results}

Literature search and selection

Our initial search yielded 3,177 records. After excluding duplicate studies, we screened a total of 1,454 titles and abstracts. Of these, 26 full-text articles met the full inclusion criteria. Two RCTs were excluded because of a lack of demographic and/or outcomes data. ${ }^{23,24} \mathrm{An}$ additional nine RCTs were excluded as they did not involve the target intervention comparison. ${ }^{25-34}$ Two additional RCTs were excluded because they were published as an abstract ${ }^{35,36}$ and one RCT was excluded because although it correlated anesthetic depth with cerebral oximetry, it did not detail the associated intervention. ${ }^{37}$ Finally, three additional trials were identified from reference lists of the articles included. ${ }^{7,38,39}$ Figure 1 outlines the full results of article selection. In total, 15 RCTs were included in this metaanalysis. $^{7,17,38-50}$

Study characteristics

The Table summarizes the characteristics of the included studies. Ten RCTs included patients undergoing cardiac surgery (coronary artery bypass, valve replacement or
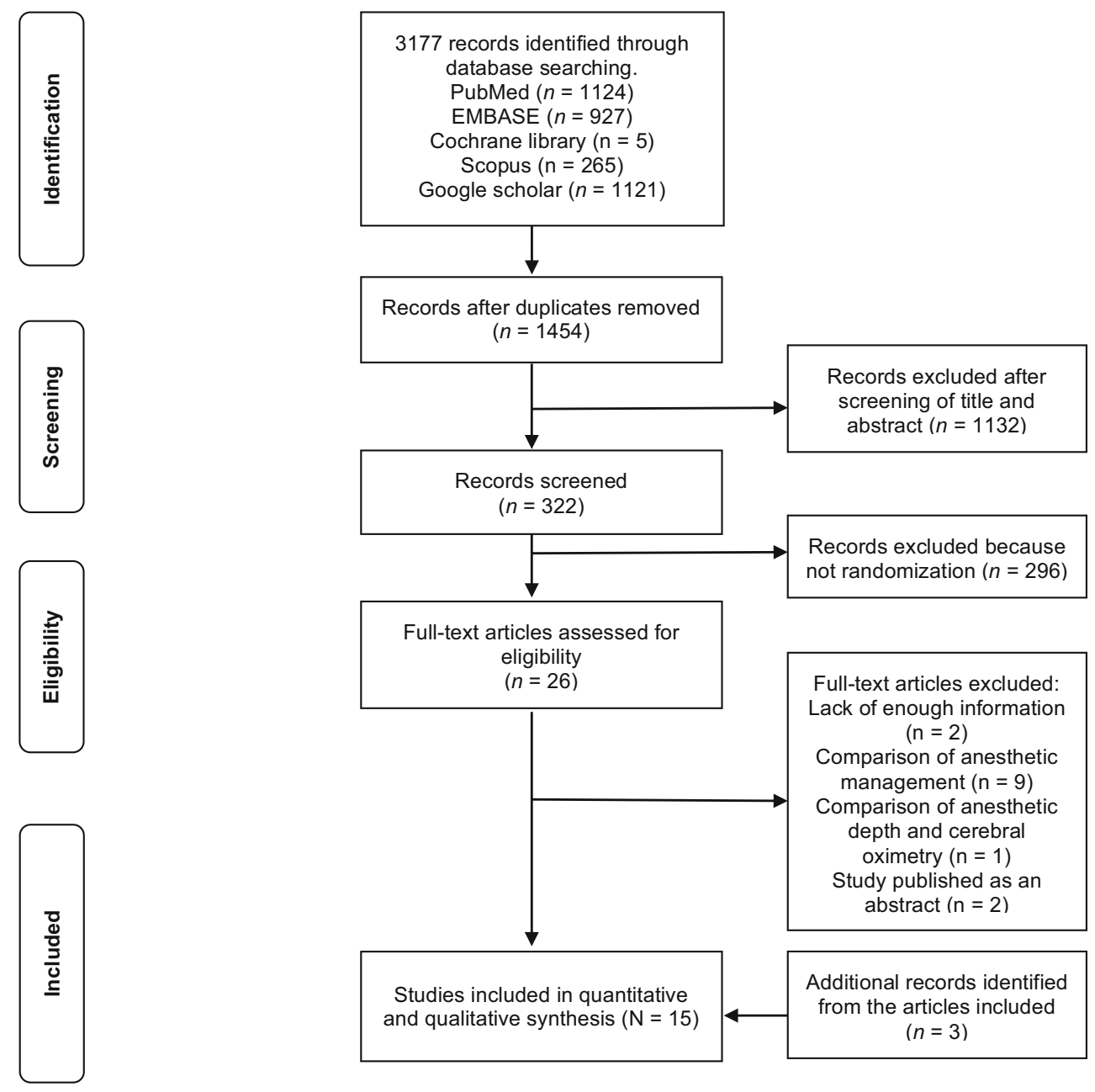

Fig. 1 PRISMA flow chart of the selection of studies 


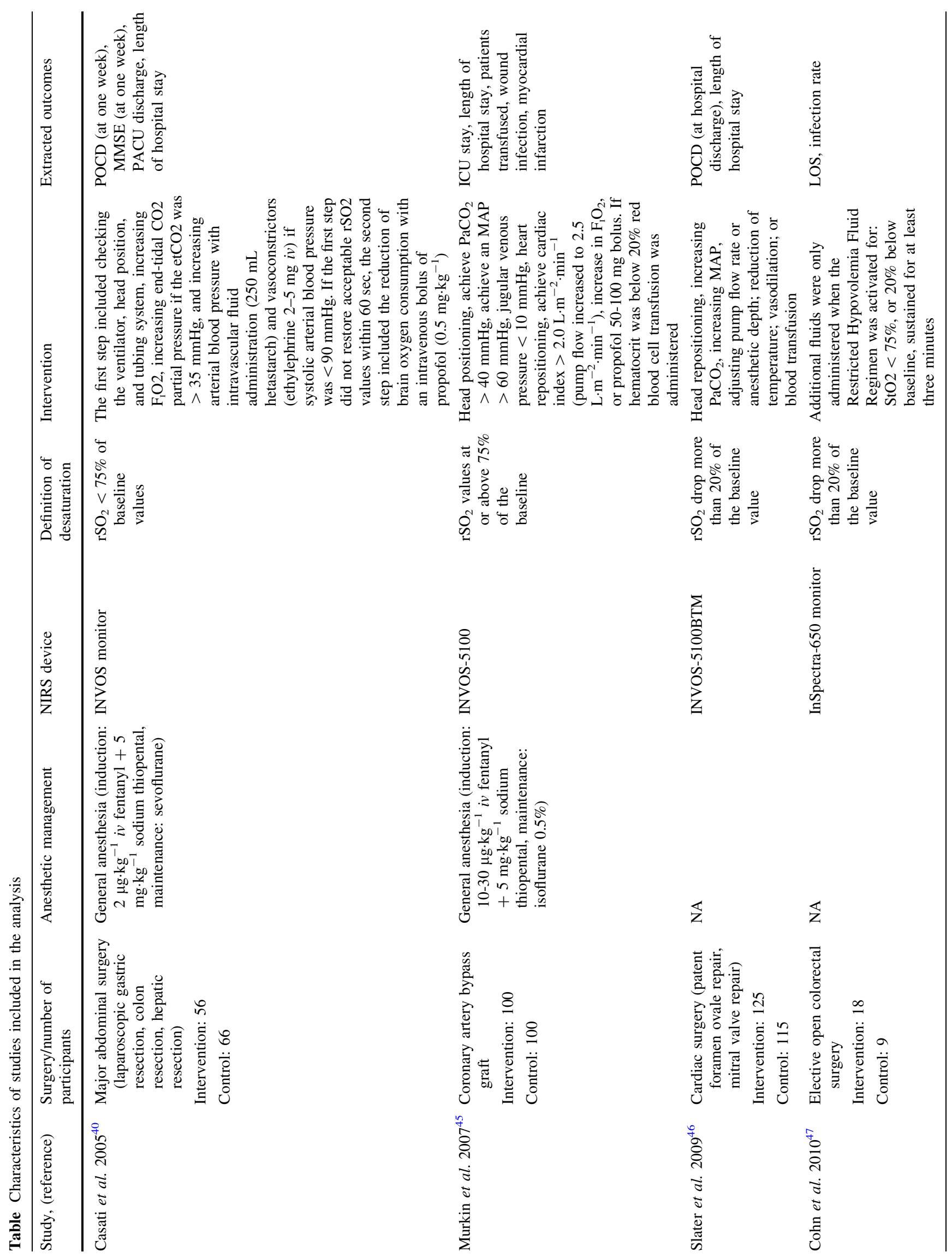




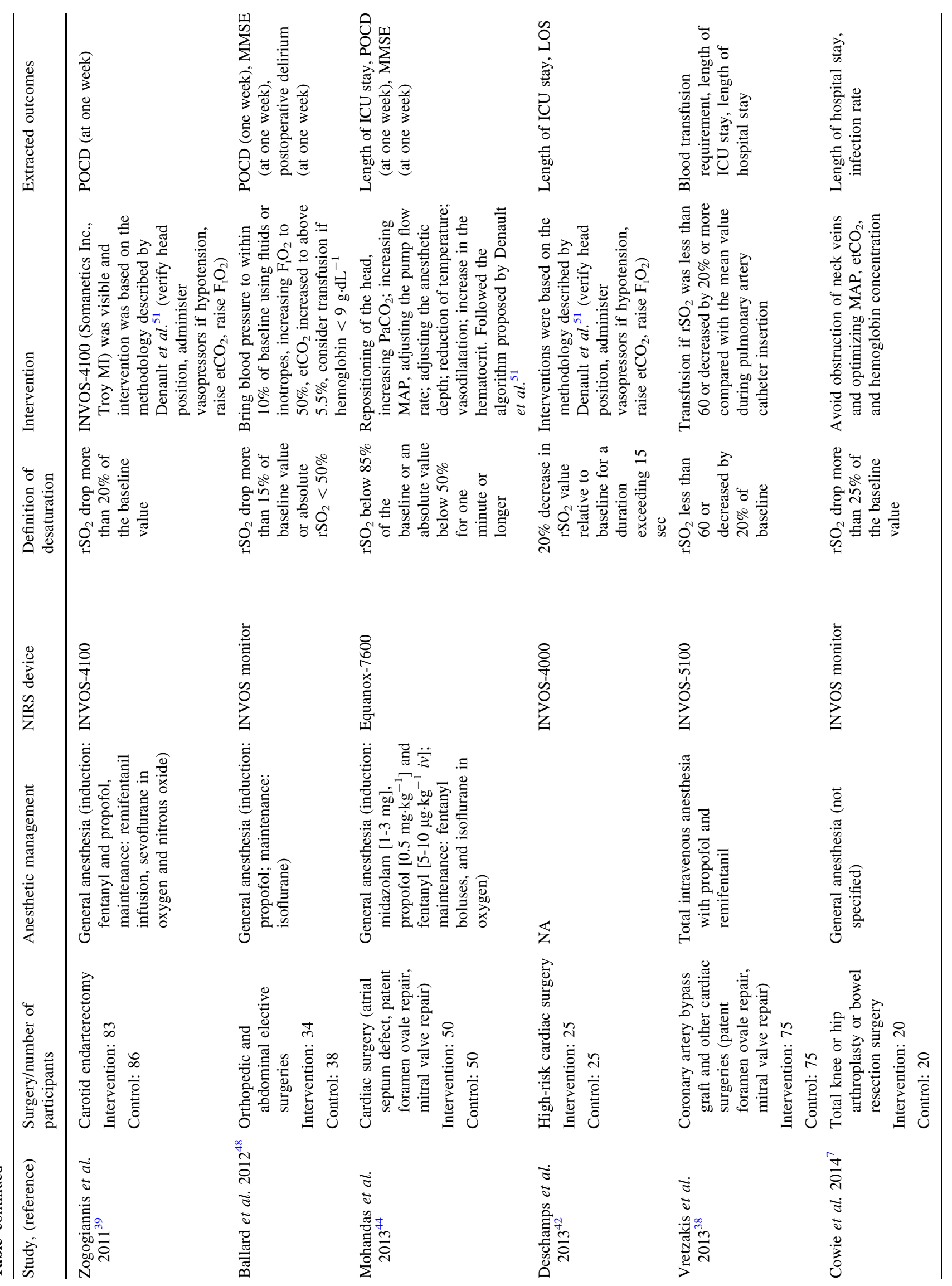




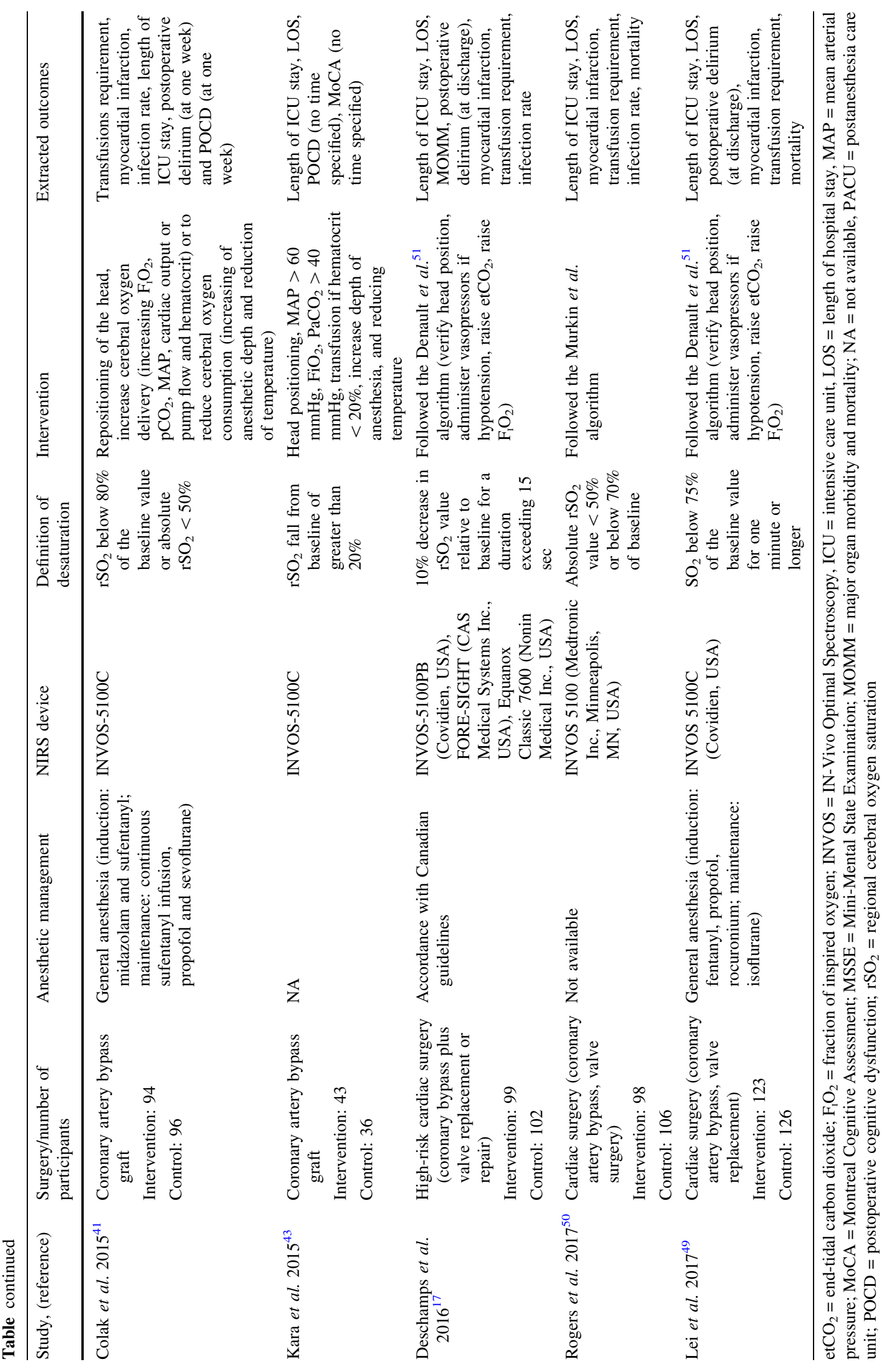




\section{(A)}

\begin{tabular}{|c|c|c|c|c|c|}
\hline \multicolumn{2}{|c|}{ Experimental } & \multicolumn{2}{|c|}{ Control } & \multirow[b]{2}{*}{ Weight } & \multirow{2}{*}{$\begin{array}{c}\text { Risk Ratio } \\
\text { M-H, Random, 95\% C }\end{array}$} \\
\hline Events & Total & Events & Total & & \\
\hline 20 & 56 & 30 & 66 & $16.4 \%$ & $0.79[0.51,1.22]$ \\
\hline 73 & 125 & 70 & 115 & $19.3 \%$ & $0.96[0.78,1.18]$ \\
\hline 10 & 83 & 11 & 86 & $11.2 \%$ & $0.94[0.42,2.10]$ \\
\hline 19 & 34 & 28 & 38 & $17.6 \%$ & $0.76[0.53,1.08]$ \\
\hline 2 & 50 & 34 & 50 & $6.0 \%$ & $0.06[0.01,0.23]$ \\
\hline 7 & 43 & 19 & 36 & $11.9 \%$ & $0.31[0.15,0.65]$ \\
\hline \multirow[t]{2}{*}{28} & 94 & 52 & 96 & $17.5 \%$ & $0.55[0.38,0.79]$ \\
\hline & 485 & & 487 & $100.0 \%$ & $0.60[0.40,0.89]$ \\
\hline $\begin{array}{r}159 \\
=0 ; \mathrm{Chi}^{2} \\
=2.54(\mathrm{P}\end{array}$ & .01 & 244 & & & $1 \%$ \\
\hline
\end{tabular}

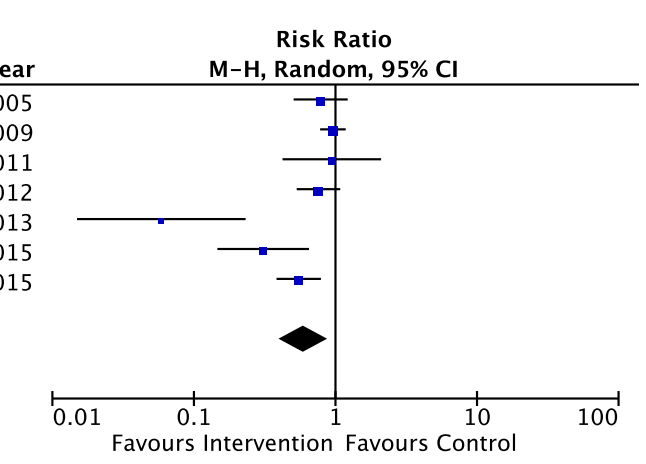

(B)

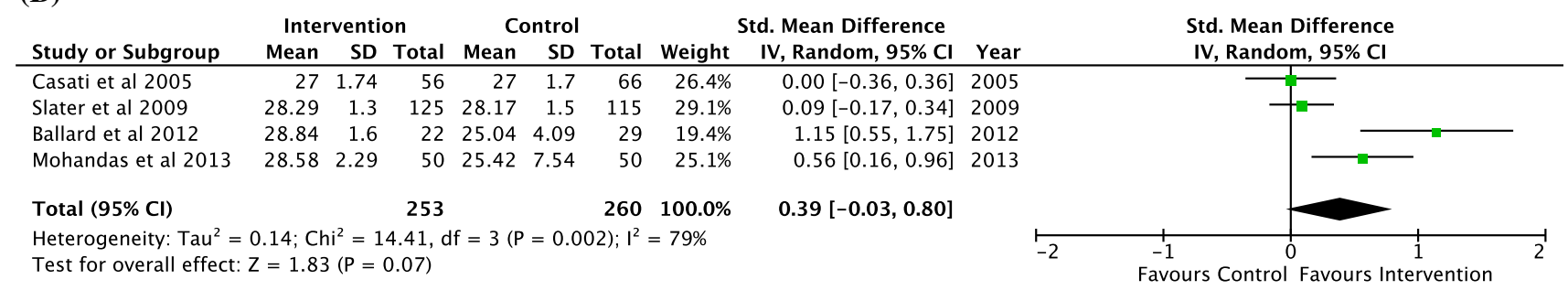

Fig. 2 Forest plots illustrating A) the incidence of postoperative cognitive dysfunction and B) Mini-Mental State Examination score between intervention and control groups

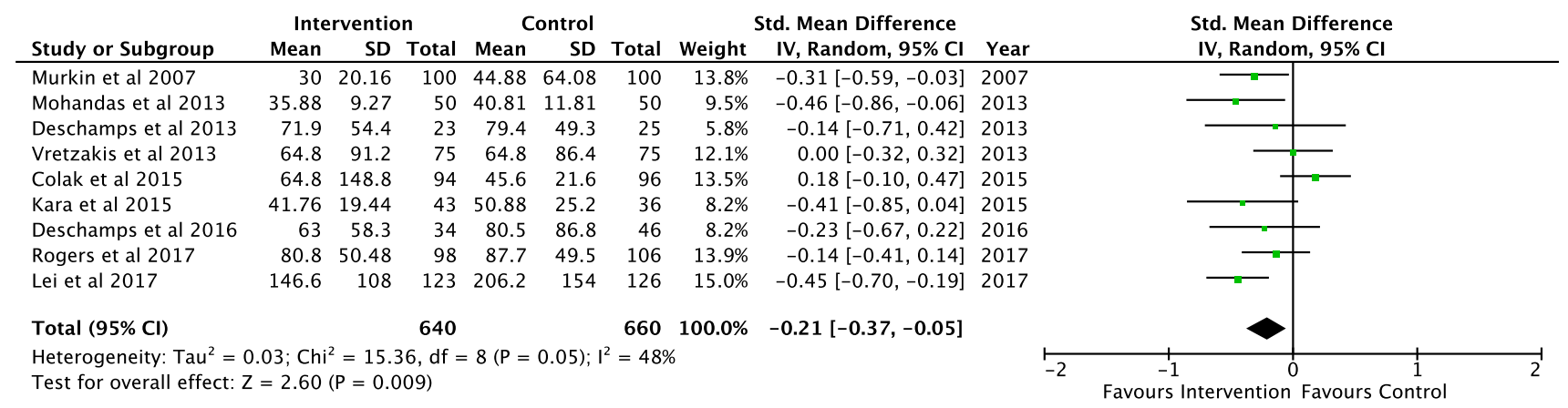

Fig. 3 Pooled effect of cerebral oximetry-guided management on the length of stay in the intensive care

repair), ${ }^{17,38,39,41-46,50}$ one $\mathrm{RCT}$ was in carotid endarterectomy surgery, ${ }^{39}$ two RCTs included only major abdominal surgery, ${ }^{40,47}$ and two RCTs included both arthroplasty and abdominal surgeries. ${ }^{7,48}$ A total of 2,057 patients (1,018 in the intervention group and 1,039 in control group) were included in the overall analysis. The intervention in 13 RCTs was the correction of cerebral oxygen desaturation (i.e., via modifying mechanical ventilation or administering vasopressors), of which seven RCTs followed an algorithm as outlined by Denault et al. ${ }^{17,39,42,44,49-51}$ while the remainder applied other individualized algorithms. The intervention in two RCTs was a combination of fluid administration and/or transfusion if $\mathrm{rSO}_{2}$ decreased by more than $20-25 \%$ below baseline. ${ }^{47}$ The Table also shows the definitions of cerebral desaturation of each study.
Primary outcome

Among the seven trials examining the primary outcome, management associated with the use of intraoperative cerebral oximetry was associated with a significant reduction in POCD at one week (Fig. 2A; RR, 0.60; 95\% CI, 0.40 to $0.89 ; P<0.001, \mathrm{I}^{2}=81 \%$ ) compared with patients who did not receive therapy guided by cerebral oximetry. Subgroup analysis that included only trials involving cardiac surgery resulted in a similar association (RR, $0.55 ; 95 \%$ CI, 0.36 to $0.86 ; P=0.009 ; \mathrm{I}^{2}=85 \%$ ), but we found no significant association in non-cardiac surgery (RR, 0.79; 95\% CI, 0.61 to $1.02 ; P=0.07 ; \mathrm{I}^{2}=0 \%$ ). Among the studies that did not follow the Denault et al. algorithm, the results again show a significant association between the use of cerebral oximetry to guide intervention 


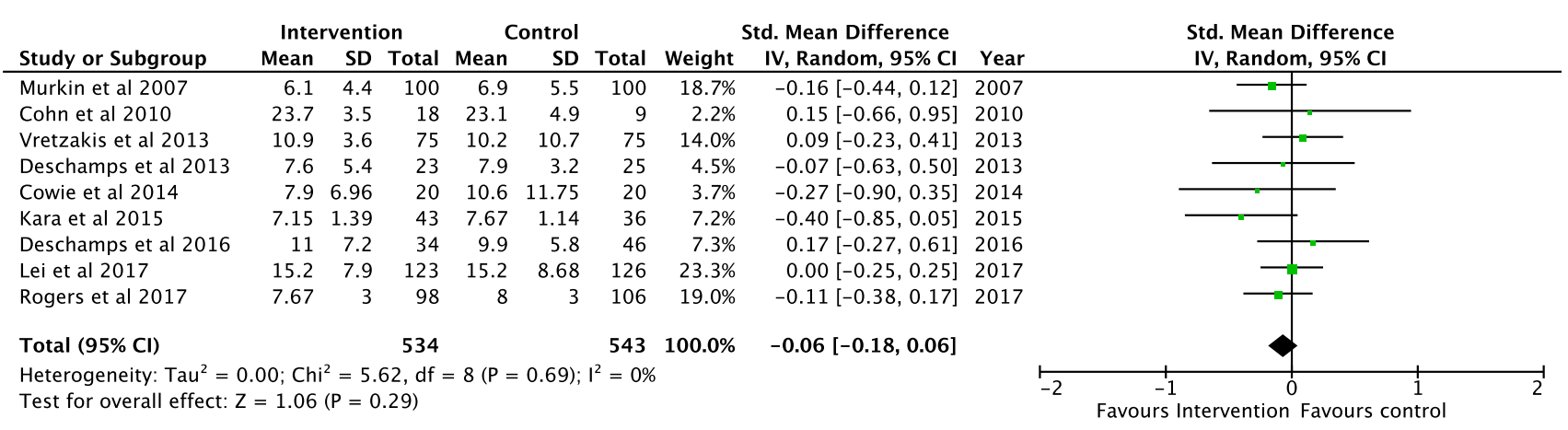

Fig. 4 Pooled effect of cerebral oximetry-guided management on length of hospital stay

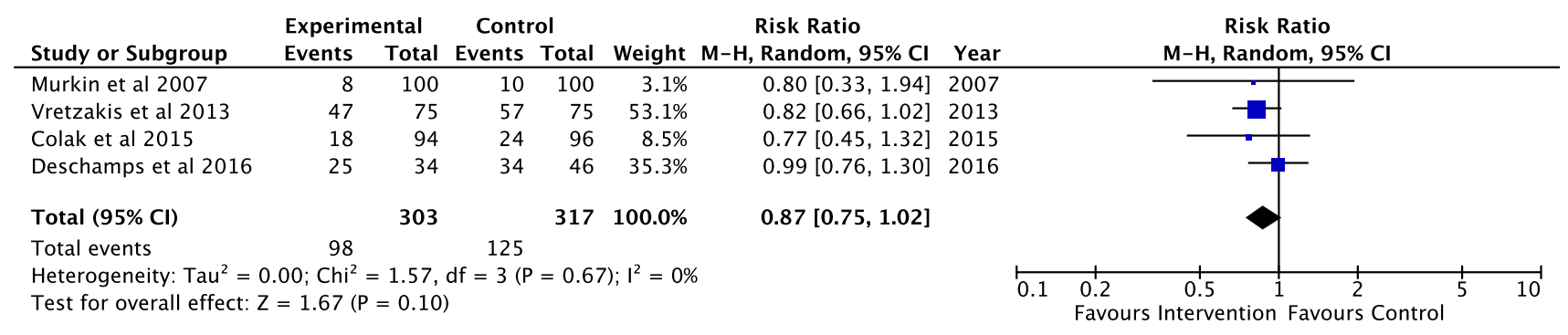

Fig. 5 Pooled effect of cerebral oximetry-guided management on incidence of total red blood cell transfusion

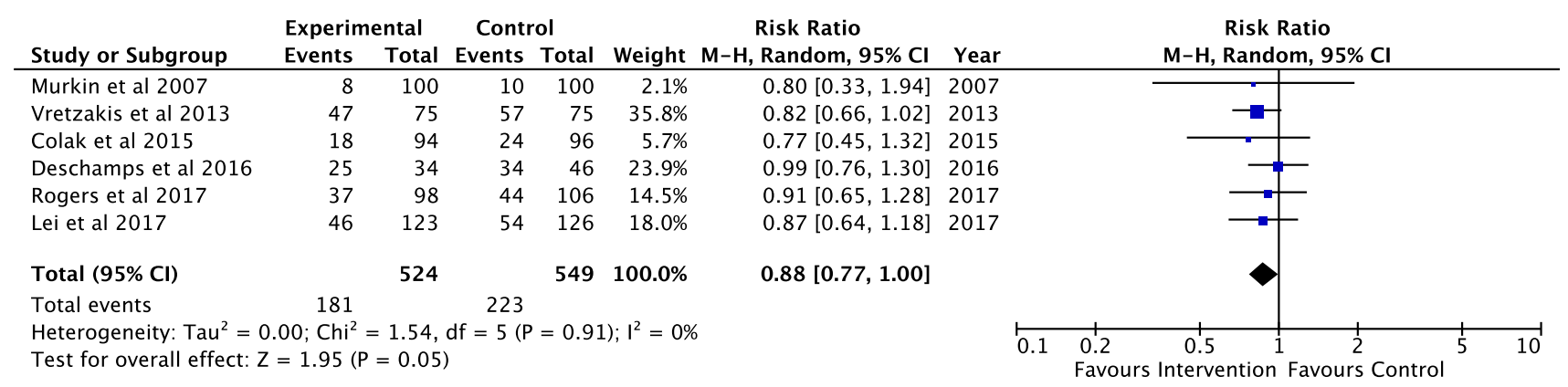

Fig. 6 Pooled effect of cerebral-oximetry guided management on incidence of postoperative delirium

and reduction in POCD (five RCTs; RR 0.6; 95\% CI, 0.50 to $0.94 ; P=0.02 ; \mathrm{I}^{2}=72 \%$ ). The use of cerebral oximetrydriven interventions was not associated with a statistically higher MMSE at one week (Fig. 2B; SMD, 0.39; 95\% CI, -0.03 to $0.80 ; P=0.07 ; \mathrm{I}^{2}=79 \%$ ) compared with controls. There was no evidence of publication bias in our analyses (Egger's test bias $=-0.05 ; P=0.96$ ). Sensitivity analysis revealed no significant differences in the overall analysis for either endpoint.

Secondary outcomes

The ICU LOS was examined in eight trials, all of which were conducted in cardiac surgery. Our results suggest that patients in the intervention group have significantly shorter lengths of ICU stay compared with the control group
(Fig. 3; SMD, $-0.21 \mathrm{hr} ; 95 \% \mathrm{CI},-0.37$ to $-0.05 ; P=$ $0.009 ; \mathrm{I}^{2}=48 \%$ ). In subgroup analysis, we found that among the studies that followed the Denault et al. algorithm, there was a significant association with a reduction in ICU stay (five RCTs; RR, $-0.31 \mathrm{hr}$; 95\% $\mathrm{CI},-0.46$ to $\left.-0.16 ; P<0.001 ; \mathrm{I}^{2}=0 \%\right)$. In contrast, there was no significant association among the studies that did not follow the Denault et al. algorithm (four RCTs; RR, $-0.11 \mathrm{hr} ; 95 \% \mathrm{CI},-0.38$ to $0.15 ; P=0.40 ; \mathrm{I}^{2}=63 \%$ ). Among the eight trials that reported on hospital LOS, pooled analysis found no significant difference between the groups (Fig. 4; SMD, -0.06 days; $95 \%$ CI, -0.18 to 0.06 ; $\left.P=0.29 ; \mathrm{I}^{2}=0 \%\right)$.

Transfusion was examined in six trials, all of which were conducted in cardiac surgery. Patients monitored with intraoperative cerebral oximetry tended to have fewer 


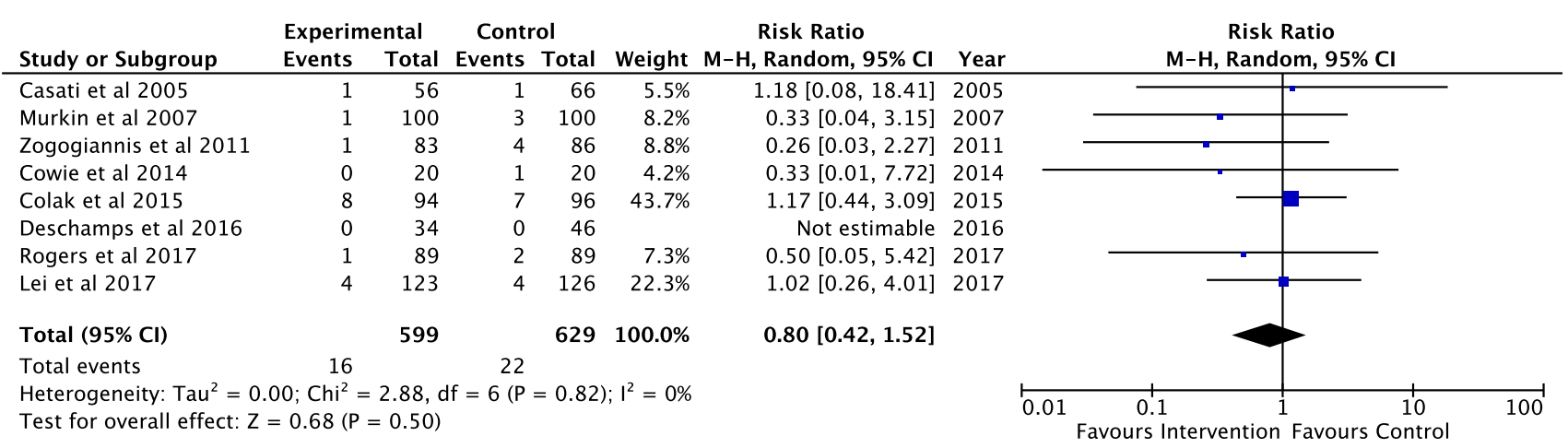

Fig. 7 Pooled effect of cerebral oximetry-guided management on incidence of postoperative myocardial infarction

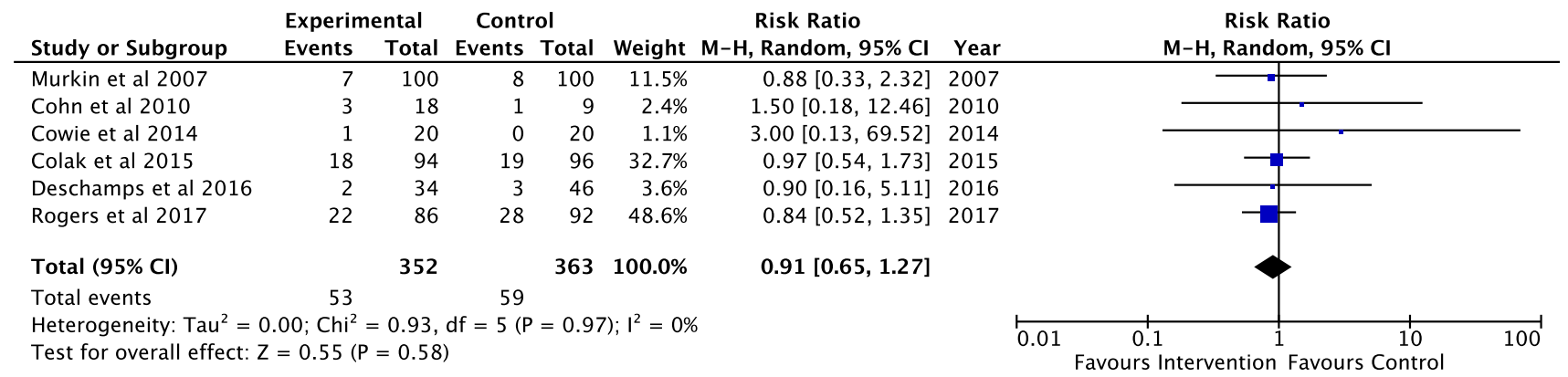

Fig. 8 Pooled effect of cerebral oximetry-guided management on incidence of postoperative surgical site infection

blood transfusions but this did not reach significance compared with the control group (Fig. 4; RR, 0.88; 95\% CI, 0.77 to $1.10 ; P=0.05 ; \mathrm{I}^{2}=0 \%$ ) (Fig. 5).

Four RCTs specifically assessed for postoperative delirium. There was no significant difference between groups in the incidence of postoperative delirium (Fig. 6; RR, $0.90 ; 95 \%$ CI, 0.63 to $1.29 ; P=0.57 ; \mathrm{I}^{2}=0 \%$ ).

The results of pooled analysis in the eight trials that reported on myocardial infarction suggested no significant difference between groups (Fig. 7; RR, 0.80; 95\% CI, 0.42 to $\left.1.52 ; P=0.50 ; \mathrm{I}^{2}=0 \%\right)$. Subgroup analysis specific to cardiac (RR, 0.98; 95\% CI, 0.46-2.06; $P=0.95 ; \mathrm{I}^{2}=0 \%$ ) and non-cardiac (RR, $0.68 ; 95 \% \mathrm{CI}, 0.09$ to $5.40 ; P=0.72$; $\left.I^{2}=0 \%\right)$ surgery yielded similar results.

Six RCTs compared the surgical site infection rates between the groups. We found no difference in the rate of infection (Fig. 8; RR, 0.91; 95\% CI, 0.65 to $1.27 ; P=0.58$; $\mathrm{I}^{2}=0 \%$ ) between groups. Mortality within 30 days of surgery was comparable between the intervention and control group (RR, $0.73 ; 95 \% \mathrm{CI}, 0.34$ to $1.58 ; P=0.42 ; \mathrm{I}^{2}$ $=0 \%)$ (Fig. 9).

\section{Methodologic quality assessment}

The electronic supplemental material (ESM) shows the assessment of study quality (ESM Table) and the funnel plots are shown in the ESM figures. We found no evidence of significant asymmetry or publication bias based upon Begg's test (for POCD, $P=0.36$; for delirium, $P=0.99$; for mortality, $P=0.29$; for surgical site infection, $P=0.99$ ). Overall, 12 studies were classified at moderate risk and two at high risk of bias. ${ }^{17,39}$ Given these results, further sensitivity analysis was not performed based upon risk of bias assessment.

\section{Discussion}

This meta-analysis assessed the effects of intraoperative cerebral oximetry-guided management on select postoperative outcomes. The results of this study suggest that interventions associated with intraoperative cerebral oximetry monitoring reduce the incidence of POCD resulting in higher MMSE scores at one week compared with a control population. Similarly we found a significant association with shorter ICU LOS in the oximetry-guided intervention group. Nevertheless, the results of our pooled analysis do not suggest a significant difference in hospital LOS or in the incidence of postoperative delirium, transfusion, surgical site infection, or myocardial infarction. 


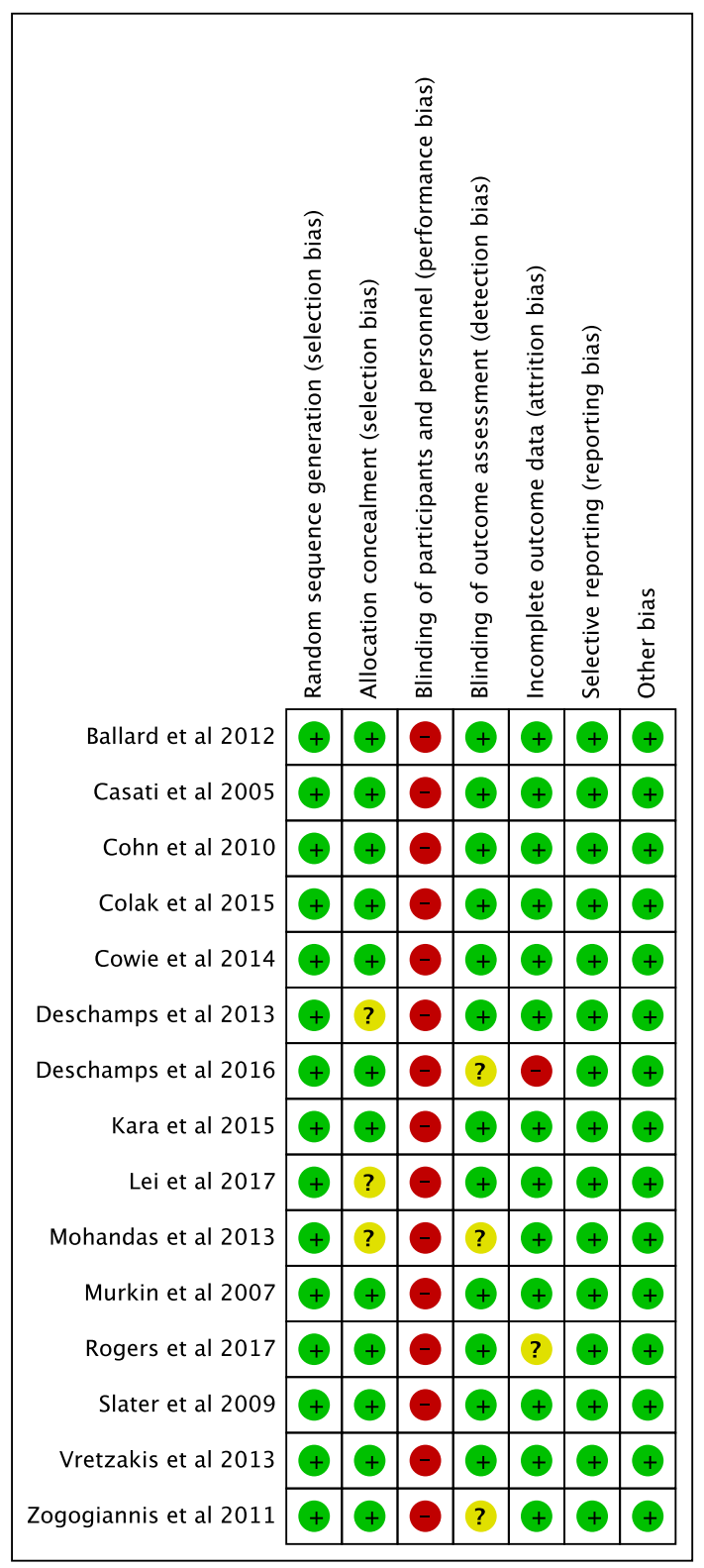

Fig. 9 Summary of the risk of bias assessment of each study

Others have performed meta-analyses to assess the effect of cerebral oximetry monitoring on outcomes after cardiac arrest as well as in extremely low birth weight infants. ${ }^{52-54}$ Cournoyer et $a l .{ }^{52}$ included 20 non-randomized studies in a meta-analysis assessing the effects of cerebral oximetry after cardiac arrest and concluded that higher regional cerebral saturation is associated with improved resuscitation outcomes, especially the return to spontaneous circulation. ${ }^{48}$ Sorensen et al. concluded that cerebral oximetry monitoring seems important for predicting neurologic complications associated with liver transplantion. ${ }^{54}$ Although these prior efforts may provide insight into the potential interventions that might stem from the use of cerebral oximetry, it is worth noting that these populations provided only limited information regarding the surrogacy of cerebral oximetry in an operative cohort. ${ }^{5,56}$

Though not meta-analyses, prior studies designed to illustrate the impact of cerebral oximetry-guided management have qualitatively evaluated the methodology in several populations. At least four systematic reviews have alluded to the potential benefit of cerebral oximetry monitoring in the cardiac surgery population. ${ }^{9,53,57,58}$ These reviews concluded that despite a limited amount of high-level clinical evidence, the majority of the literature supports the link of cerebral oximetry monitoring to the prevention of POCD. Indeed, Taillefer et al. published a systematic review regarding the use of cerebral oximetry in cardiac surgery, though the authors included only a single RCT, ${ }^{36}$ and rightfully concluded that this topic had not yet been sufficiently investigated with the rigour necessary to make a more definitive statement regarding the role of cerebral oximetry in adult cardiac surgery. ${ }^{53}$ It is worth mentioning that the review article of Taillefer et al. was conducted before the publication of the first RCT in cerebral oximetry. ${ }^{40}$ Our analysis was designed to address this limitation through the inclusion of only RCTs that incorporated interventions guided by the use of cerebral oximetry. Furthermore, we primarily investigated the cognitive impact of these interventions.

There are several possible explanations for the association between cerebral oximetry monitoring during surgery and reduction in POCD. Certainly, it is logical to conclude that the reduction in the incidence of low intraoperative cerebral saturation levels (i.e., indicative of potential cerebral hypoxia) might lead to a subsequent reduction in POCD. This is further supported to be a simple mechanism for benefit by other observational studies. A more nuanced interpretation is that POCD is likely secondary to a relative decrease in effective cerebral perfusion. This may be the downstream result of inadequate arterial blood pressure, cerebral autoregulation impairment, or other unidentified hemodynamic indices. ${ }^{59}$ While our analysis is unable to specifically evaluate each of these players, cerebral oximetry may represent a useful final common pathway for interpretation of a low perfusion state. Therefore, interventions designed to address one (or all) of these potential variables may provide benefit in reducing the incidence of POCD.

Although our analysis supports the benefit of cerebral oximetry-guided management on the incidence of POCD and a shorter length of ICU stay, it does not show similar impact among a number of other secondary clinical outcomes. Observational studies have previously shown an association between low cerebral oxygen saturation and postoperative delirium. ${ }^{3,60}$ Others have shown that the severity or duration of postoperative delirium may ultimately be related to subsequent POCD. ${ }^{61}$ While our 
analysis did not confirm these results, it is quite possible our pooled analysis included too few patients to adequately assess for postoperative delirium. Furthermore, it is equally plausible that patients may develop POCD without showing signs of early postoperative delirium.

There are several potential implications of these study results. First, they suggest that intraoperative management guided by cerebral oximetry may have applications in the postoperative period. Interventions designed to maintain baseline cerebral perfusion and/or oxygen saturation may prevent POCD and even reduce the length of ICU stay. Second, the interventions described among the included studies are relatively simple and largely include modifications to ventilation strategies, supplementation of additional oxygen, or application of vasopressor support. These do not represent particularly invasive strategies, and therefore it would not be difficult or particularly controversial to begin to develop goal-directed cerebral perfusion protocols based upon the interventions associated with these included trials.

Several important limitations are associated with our meta-analysis. First, the results of our primary analysis were associated with a significant degree of heterogeneity probably due to the different types of cerebral oximetrybased interventions as well as variations in the definition of cerebral oxygen desaturation, the different combinations of cognitive tests that were used to define POCD among the studies, varying surgical case mixes, and other potential differences in individual study-specific patient populations. A number of strategies were utilized to attempt to determine the cause of this level of heterogeneity, including the use of a random effects model, assessment for publication bias, employment of subgroup analysis, and risk of bias assessment. Second, the relatively short time frame that POCD was assessed (i.e., one week postoperatively) could limit the clinical significance of our findings; however it is important to note that only two trials assessed this outcome at three months and both showed significant reduction of POCD in the intervention group. ${ }^{44,48}$ Another limitation of this meta-analysis is the small sample size of the included RCTs. This highlights the need for further large randomized trials designed to investigate similar intervention strategies surrounding the use of intraoperative cerebral oximetry. Although our analysis failed to show a significant association between the use of cerebral oximetry and other secondary outcomes, this may in part be a function of either a low overall incidence of complications or a lack of adequate patient numbers to detect meaningful differences. After searching the databases and international registries of RCTs, we found two completed but not published RCTs (NCT02155868, ISRCTN23557269) and an ongoing RCT
(NCT01707446). Similar future initiatives are likely to add substantial clarity to a rapidly evolving field.

In conclusion, intraoperative cerebral oximetry-guided management is associated with significant reduction in the incidence of POCD. Providers may consider the application of cerebral oximetry to inform specific interventions geared towards minimizing cerebral desaturation and hypoperfusion. Although further large high-quality trials are necessary to elucidate which interventions are most effective and how they directly impact cognitive dysfunction, our findings suggest that simple intraoperative maneuvers based upon cerebral oximetry may provide clear benefit.

Conflicts of interest Dr. Lucia Rivera Lara received a grant from Medtronic/Covidien, Dublin, Ireland.

Author contributions Andres Zorrilla-Vaca contributed to the study conception and design, drafting the manuscript, acquisition of data, and analysis and interpretation of data. Ryan Healy was involved in drafting the manuscript and literature search. Michael C. Grant was involved in drafting the manuscript and revising it for important intellectual content. Brijen Joshi was involved in drafting the manuscript and revising it for important intellectual content. Lucia Rivera-Lara was involved in drafting the manuscript and revising it for important intellectual content. Charles Brown was involved in drafting the manuscript and revising it for important intellectual content. Marek A. Mirski was involved in drafting the manuscript and revising it for important intellectual content.

Editorial responsibility This submission was handled by Dr. Hilary P. Grocott, Editor-in-Chief, Canadian Journal of Anesthesia.

Financial support There was no funding source for this study. No authors were paid to write this article.

\section{References}

1. Green MS, Sehgal S, Tariq R. Near-infrared spectroscopy: the new must have tool in the intensive care unit? Semin Cardiothorac Vasc Anesth 2016; 20: 213-24.

2. Moerman A, De Hert S. Cerebral oximetry: the standard monitor of the future? Curr Opin Anaesthesiol 2015; 28: 703-9.

3. Mailhot T, Cossette S, Lambert J, Cournoyer A, Denault AY. Cerebral oximetry as a biomarker of postoperative delirium in cardiac surgery patients. J Crit Care 2016; 34: 17-23.

4. Sun X, Ellis J, Corso PJ, et al. Mortality predicted by preinduction cerebral oxygen saturation after cardiac operation. Ann Thorac Surg 2014; 98: 91-6.

5. Schoen J, Meyerrose J, Paarmann H, Heringlake M, Hueppe M, Berger $K U$. Preoperative regional cerebral oxygen saturation is a predictor of postoperative delirium in on-pump cardiac surgery patients: a prospective observational trial. Crit Care 2011; 15 : R218.

6. Parnia S, Yang J, Nguyen $R$, et al. Cerebral oximetry during cardiac arrest: a multicenter study of neurologic outcomes and survival. Crit Care Med 2016; 44: 1663-74. 
7. Cowie DA, Nazareth J, Story DA. Cerebral oximetry to reduce perioperative morbidity. Anaesth Intensive Care 2014; 42: 310-4.

8. Ono $M$, Brady $K$, Easley RB, et al. Duration and magnitude of blood pressure below cerebral autoregulation threshold during cardiopulmonary bypass is associated with major morbidity and operative mortality. J Thorac Cardiovasc Surg 2014; 147: 483-9.

9. Vohra HA, Modi A, Ohri SK. Does use of intra-operative cerebral regional oxygen saturation monitoring during cardiac surgery lead to improved clinical outcomes? Interact Cardiovasc Thorac Surg 2009; 9: 318-22.

10. Sanfilippo F, Serena $G$, Corredor $C$, et al. Cerebral oximetry and return of spontaneous circulation after cardiac arrest: a systematic review and meta-analysis. Resuscitation 2015; 94: 67-72.

11. Severdija EE, Vranken NP, Teerenstra S, Ganushchak YM, Weerwind $P W$. Impact of intraoperative events on cerebral tissue oximetry in patients undergoing cardiopulmonary bypass. J Extra Corpor Technol 2015; 47: 32-7.

12. Funk DJ, Kumar A, Klar G. Decreases in cerebral saturation in patients with septic shock are associated with increased risk of death: a prospective observational single center study. J Intensive Care 2016; 4: 42.

13. Fischer $G W$, Lin HM, Krol M, et al. Noninvasive cerebral oxygenation may predict outcome in patients undergoing aortic arch surgery. J Thorac Cardiovasc Surg 2011; 141: 815-21.

14. Goldman SM, Sutter FP, Wertan MA, Ferdinand FD, Trace CL, Samuels LE. Outcome improvement and cost reduction in an increasingly morbid cardiac surgery population. Semin Cardiothorac Vasc Anesth 2006; 10: 171-5.

15. Moher D, Liberati A, Tetzlaff J. Altman DG; PRISMA Group. Preferred reporting items for systematic reviews and metaanalyses: the PRISMA statement. PLoS Med 2009; 6: e1000097.

16. Higami $T$, Kozawa $S$, Asada $T$, et al. Retrograde cerebral perfusion versus selective cerebral perfusion as evaluated by cerebral oxygen saturation during aortic arch reconstruction. Ann Thorac Surg 1999; 67: 1091-6.

17. Deschamps A, Hall $R$, Grocott $H$, et al. Cerebral oximetry monitoring to maintain normal cerebral oxygen saturation during high-risk cardiac surgery: a randomized controlled feasibility trial. Anesthesiology 2016; 124: 826-36.

18. Higgins JP, Altman DG, Gotzsche PC, et al. The Cochrane Collaboration's tool for assessing risk of bias in randomised trials. BMJ 2011; 343: d5928.

19. Berg AO, Allan JD. Introducing the third US Preventive Services Task Force. Am J Prevent Med 2001; 20(3 Suppl): 3-4.

20. Wan X, Wang W, Liu J, Tong T. Estimating the sample mean and standard deviation from the sample size, median, range and/or interquartile range. BMC Med Res Methodol 2014; 14: 135.

21. Egger M, Davey Smith $G$, Schneider M, Minder $C$. Bias in metaanalysis detected by a simple, graphical test. BMJ 1997; 315: 629-34.

22. DerSimonian $R$, Kacker $R$. Random-effects model for metaanalysis of clinical trials: an update. Contemp Clin Trials 2007; 28: $105-14$

23. Lomivorotov VV, Perovskiy P, Fominskiy E, et al. Cerebral oximetry in reducing postoperative morbidity in high-risk cardiac surgery. J Cardiothorac Vasc Anesth 2017; 31: S48-9.

24. Trafidlo T, Gaszynski T, Gaszynski W, Nowakowska-Domagala $K$. Intraoperative monitoring of cerebral NIRS oximetry leads to better postoperative cognitive performance: a pilot study. Int $\mathbf{J}$ Surg 2015; 16(Pt A): 23-30.

25. Cho SY, Kim SJ, Jeong CW, et al. Under general anesthesia arginine vasopressin prevents hypotension but impairs cerebral oxygenation during arthroscopic shoulder surgery in the beach chair position. Anesth Analg 2013; 117: 1436-43.
26. Fassoulaki A, Kaliontzi H, Petropoulos G, Tsaroucha A. The effect of desflurane and sevoflurane on cerebral oximetry under steady-state conditions. Anesth Analg 2006; 102: 1830-5.

27. Guclu CY, Unver S, Aydinli B, Kazanci D, Dilber E, Ozgok A. The effect of sevoflurane vs. TIVA on cerebral oxygen saturation during cardiopulmonary bypass-randomized trial. Adv. Clin Exp Med 2014; 23: 919-24.

28. Kok WF, van Harten AE, Koene BM, et al. A pilot study of cerebral tissue oxygenation and postoperative cognitive dysfunction among patients undergoing coronary artery bypass grafting randomised to surgery with or without cardiopulmonary bypass. Anaesthesia 2014; 69: 613-22.

29. Mayr NP, Hapfelmeier A, Martin K, et al. Comparison of sedation and general anaesthesia for transcatheter aortic valve implantation on cerebral oxygen saturation and neurocognitive outcome. Br J Anaesth 2016; 116: 90-9.

30. Meng L, Cannesson $M$, Alexander BS, et al. Effect of phenylephrine and ephedrine bolus treatment on cerebral oxygenation in anaesthetized patients. Br J Anaesth 2011; 107 : 209-17.

31. Murphy GS, Szokol JW, Marymont JH, et al. Cerebral oxygen desaturation events assessed by near-infrared spectroscopy during shoulder arthroscopy in the beach chair and lateral decubitus positions. Anesth Analg 2010; 111: 496-505.

32. Taussky P, O'Neal B, Daugherty WP, et al. Validation of frontal near-infrared spectroscopy as noninvasive bedside monitoring for regional cerebral blood flow in brain-injured patients. Neurosurg Focus 2012; 32: E2.

33. Valencia L, Rodriguez-Perez A, Kuhlmorgen B, Santana RY. Does sevoflurane preserve regional cerebral oxygen saturation measured by near-infrared spectroscopy better than propofol? Ann Fr Anesth Reanim 2014; 33: e59-65.

34. Picton P, Dering A, Alexander A, et al. Influence of ventilation strategies and anesthetic techniques on regional cerebral oximetry in the beach chair position: a prospective interventional study with a randomized comparison of two anesthetics. Anesthesiology 2015; 123: 765-74.

35. Baker RA, Knight JL. The OXICAB trial: cerebral oximetry in adult cardiac surgical patients. J Extra Corpor Technol 2006; 38 : 77.

36. Iglesias I, Murkin J, Bainbridge D, Adams S. Monitoring cerebral oxygen saturation significantly decreases postoperative length of stay: a prospective randomized blinded study. Heart Surg Forum 2003: 204 (abstract).

37. Hu Z, Хи L, Zhu Z, Seal R, McQuillan PM. Effects of hypothermic cardiopulmonary bypass on internal jugular bulb venous oxygen saturation, cerebral oxygen saturation, and bispectral index in pediatric patients undergoing cardiac surgery: a prospective study. Medicine (Baltimore) 2016; 95: e2483.

38. Vretzakis G, Georgopoulou S, Stamoulis $K$, et al. Monitoring of brain oxygen saturation (INVOS) in a protocol to direct blood transfusions during cardiac surgery: a prospective randomized clinical trial. J Cardiothorac Surg 2013; 8: 145.

39. Zogogiannis I, Iatrou C, Lazarides $M K$, et al. Evaluation of an intraoperative algorithm based on near-infrared refracted spectroscopy monitoring, in the intraoperative decision for shunt placement, in patients undergoing carotid endarterectomy. Middle East J Anaesthesiol 2011; 21: 367-73.

40. Casati A, Fanelli G, Pietropaoli P, et al. Continuous monitoring of cerebral oxygen saturation in elderly patients undergoing major abdominal surgery minimizes brain exposure to potential hypoxia. Anesth Analg 2005; 101: 740-7. 
41. Colak Z, Borojevic M, Bogovic A, Ivancan V, Biocina B, MajericKogler $V$. Influence of intraoperative cerebral oximetry monitoring on neurocognitive function after coronary artery bypass surgery: a randomized, prospective study. Eur J Cardiothorac Surg 2015; 47: 447-54.

42. Deschamps A, Lambert J, Couture P, et al. Reversal of decreases in cerebral saturation in high-risk cardiac surgery. J Cardiothorac Vasc Anesth 2013; 27: 1260-6.

43. Kara I, Erkin A, Sacli H, et al. The effects of near-infrared spectroscopy on the neurocognitive functions in the patients undergoing coronary artery bypass grafting with asymptomatic carotid artery disease: a randomized prospective study. Ann Thorac Cardiovasc Surg 2015; 21: 544-50.

44. Mohandas BS, Jagadeesh AM, Vikram SB. Impact of monitoring cerebral oxygen saturation on the outcome of patients undergoing open heart surgery. Ann Cardiac Anaesth 2013; 16: 102-6.

45. Murkin JM, Adams SJ, Novick RJ, et al. Monitoring brain oxygen saturation during coronary bypass surgery: a randomized, prospective study. Anesth Analg 2007; 104: 51-8.

46. Slater JP, Guarino T, Stack J, et al. Cerebral oxygen desaturation predicts cognitive decline and longer hospital stay after cardiac surgery. Ann Thorac Surg 2009; 87: 36-44; discussion 44-5.

47. Cohn SM, Pearl RG, Acosta SM, et al. A prospective randomized pilot study of near-infrared spectroscopy-directed restricted fluid therapy versus standard fluid therapy in patients undergoing elective colorectal surgery. Am Surg 2010; 76: 1384-92.

48. Ballard $C$, Jones $E$, Gauge $N$, et al. Optimised anaesthesia to reduce post operative cognitive decline (POCD) in older patients undergoing elective surgery, a randomised controlled trial. PloS One 2012; 7: e37410.

49. Lei L, Katznelson R, Fedorko L, et al. Cerebral oximetry and postoperative delirium after cardiac surgery: a randomised, controlled trial. Anaesthesia 2017; 72: 1456-66.

50. Rogers $C$, Stoica $S$, Ellis $L$, et al. Randomized trial of nearinfrared spectroscopy for personalized optimization of cerebral tissue oxygenation during cardiac surgery. Br J Anaesth 2017; 119: 384-93.
51. Denault A, Deschamps A, Murkin JM. A proposed algorithm for the intraoperative use of cerebral near-infrared spectroscopy. Semin Cardiothorac Vasc Anesth 2007; 11: 274-81.

52. Cournoyer A, Iseppon M, Chauny JM, Denault A, Cossette S, Notebaert E. Near-infrared spectroscopy monitoring during cardiac arrest: a systematic review and meta-analysis. Acad Emerg Med 2016; 23: 851-62.

53. Taillefer $M C$, Denault $A Y$. Cerebral near-infrared spectroscopy in adult heart surgery: systematic review of its clinical efficacy. Can J Anesth 2005; 52: 79-87.

54. Sorensen H, Grocott HP, Secher NH. Near infrared spectroscopy for frontal lobe oxygenation during non-vascular abdominal surgery. Clin Physiol Funct Imaging 2016; 36: 427-35.

55. Rivera-Lara L, Zorrilla-Vaca A, Geocadin R, et al. Predictors of outcome with cerebral autoregulation monitoring: a systematic review and meta-analysis. Crit Care Med 2017; 45: 695-704.

56. Rivera-Lara L, Zorrilla-Vaca A, Geocadin RG, Healy RJ, Ziai W, Mirski MA. Cerebral autoregulation-oriented therapy at the bedside: a comprehensive review. Anesthesiology 2017; 126: 1187-99.

57. Douds MT, Straub EJ, Kent AC, Bistrick CH, Sistino JJ. A systematic review of cerebral oxygenation-monitoring devices in cardiac surgery. Perfusion 2014; 29: 545-52.

58. Zheng $F$, Sheinberg $R$, Yee MS, Ono M, Zheng $Y$, Hogue $C W$. Cerebral near-infrared spectroscopy monitoring and neurologic outcomes in adult cardiac surgery patients: a systematic review. Anesth Analg 2013; 116: 663-76.

59. Green $D W$, Kunst $G$. Cerebral oximetry and its role in adult cardiac, non-cardiac surgery and resuscitation from cardiac arrest. Anaesthesia 2017; 72(Suppl 1): 48-57.

60. Lopez MG, Pandharipande P, Morse $J$, et al. Intraoperative cerebral oxygenation, oxidative injury, and delirium following cardiac surgery. Free Radic Biol Med 2017; 103: 192-8.

61. Wacker $P$, Nunes PV, Cabrita H, Forlenza OV. Post-operative delirium is associated with poor cognitive outcome and dementia. Dement Geriatr Cogn Disord 2006; 21: 221-7. 